\title{
Michelle Tricot, Solange, fille de George Sand
}

\section{Henriette Bessis}

\section{(2) OpenEdition}

\section{Journals}

\section{Édition électronique}

URL : http://journals.openedition.org/studifrancesi/33446

DOI : 10.4000/studifrancesi.33446

ISSN : 2427-5856

\section{Éditeur}

Rosenberg \& Sellier

\section{Édition imprimée}

Date de publication : 1 décembre 2005

Pagination : 664-665

ISSN : 0039-2944

\section{Référence électronique}

Henriette Bessis, « Michelle Tricot, Solange, fille de George Sand», Studi Francesi [En ligne], 147 (XLX

III) | 2005, mis en ligne le 30 novembre 2015, consulté le 19 avril 2021. URL : http://

journals.openedition.org/studifrancesi/33446 ; DOI : https://doi.org/10.4000/studifrancesi.33446

Ce document a été généré automatiquement le 19 avril 2021.

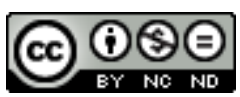

Studi Francesi è distribuita con Licenza Creative Commons Attribuzione - Non commerciale - Non opere derivate 4.0 Internazionale. 


\title{
Michelle Tricot, Solange, fille de George Sand
}

\author{
Henriette Bessis
}

\section{RÉFÉRENCE}

MICHELLE TRICOT, Solange, fille de George Sand, Paris, L'Harmattan, 2004, pp. 391.

1 Enfin un ouvrage, fondé sur des archives inédites, entièrement consacré à Solange Sand, nous permettant de mieux la connaître, même si elle porte toujours le statut difficile de fille de l'écrivain! Michelle Tricot ne néglige aucune des diverses facettes de sa personnalité. Elle s'appuie sur les papiers communiqués par Christiane Sand ou ses recherches personnelles, ce qui nous fait d'autant plus regretter quelques erreurs d'impression et fautes d'orthographe. Nous faisons vraiment connaissance avec Solange la mal aimée par sa mère, la mal considérée, grâce à de beaux portraits, tel celui écrit par Marie d'Agoult sur la jeune adolescente: «Elle est une belle fille admirablement proportionnée; elle est alerte et vigoureuse, pleine de grâce dans sa force... âme aussi forte que son corps; [...] cœur aimant, caractère passionné, indomptable. Sa vie sera pleine de luttes et de combats, Solange est destinée à l'absolu dans le bien et le mal. Elle ne se pliera pas aux règles communes: il y aura de la grandeur dans ses fautes, de la sublimité dans ses vertus». Quelle prescience chez cette grande amie de George Sand! Elle mentionne de plus, dans ses Mémoires, que Solange montre un esprit «éveillé aux curiosités de la vie», sait jouer du piano, coudre et dessiner; et M. Tricot d'ajouter qu'elle s'intéresse à une grande diversité de sujets et, dès le séjour majorquin, se montre fière, indocile, rebelle, mais aimante et heureuse de vivre.

2 À Paris, George Sand est occupée par les répétitions de ses pièces, auxquelles sa fille ne doit pas assister. Michelle Tricot précise bien qu'elle a, incontestablement, souvent mal agi envers Solange; mais celle-ci était cependant très attachée à cette mère d'attitude souvent "singulière», l'admirant comme un modèle auquel elle s'efforce de ressembler, au point parfois de copier ses manières ou ses habitudes, par exemple d'écrire la nuit. 
Solange avoue n'aimer qu'elle et sa propre fille, toutes trois partageant à Nohant «des moments savoureux» que seul le décès de Jeanne, dite Nini, interrompra.

3 L'on connaissait bien les rapports difficiles de George avec son gendre, le sculpteur Clésinger, mais moins que, malgré le divorce, Solange et lui ont continué à se fréquenter, ce que révèlent les archives familiales. De même, le portrait du père des enfants de George sort modifié de cette lecture: il n'occupait certes pas une grande place, mais son statut de père lui occasionnait tout de même des visites filiales et parfois même des emprunts d'argent!

4 Solange est très entourée d'amis et d'amants; cependant on la sent «aigrie et désabusée»: «elle voudrait être aimée pour elle-même et non pour son génie (sic) et son esprit délicat». Elle part rejoindre le comte Alfiéri, ce qui lui inspire quelques pages sur l'Italie «fort appréciées par sa mère». Sa description est agréable et vivante, s'enthousiasmant sur Sorrente: "C'est beau mais beau! Non, c'est-à-dire c'est joli, ravissant, merveilleux! Tout en argent, en azur, en couleur feuille de rose du Bengale et feuille de rose thé safrané».

5 En 1870 une bonne critique accueille son premier ouvrage paru dans la Revue des deux mondes, soulignant sa «fougue» et sa «passion». Mais, lorsqu'elle écrit Carl Robert, trois années plus tard, malgré la recommandation de George au directeur du Temps sur ce «très joli roman», «délicat et recherché», «travaillé d'après [s]es petites critiques», Solange ne trouve pas d'éditeur et reçoit même d'Émile Aucante une lettre sur sa légèreté d'écriture.

6 C'est que Solange ne reste pas en place: malgré son attachement à Montgivray où elle s'est installée un peu à l'écart de Nohant, elle aime voyager, recevoir des amis et se distraire. M. Tricot nous la décrit comme menant une vie instable et trépidante, tout en lisant beaucoup et écrivant «des lettres magnifiques»; elle tourne à la réplique de sa mère, jouant «la bonne Solange», tout comme «la bonne dame de Nohant», férue de recherches historiques, pratiquant des fouilles dans son domaine.

7 Lors d'un séjour à Paris, elle fait la connaissance d'une famille égyptienne, très attachée à la culture française; elle se lie très intimement à la jeune princesse Nazli. Michelle Tricot insiste fortement sur la bonté et la douceur de Solange, vraisemblablement pour nous convaincre du caractère excessif de sa renommée péjorative. Elle décrit ses très nombreuses amitiés, jamais démenties; cite des fragments de lettres de ses correspondants attestant de leur affection. Par exemple, Marie Jaell, amie de Liszt et de Chopin, lui envoie régulièrement ses ouvrages, notamment sur la musique et la psychophysiologie. Solange lui répond, en une lettre importante pour la vraie perception de sa personnalité: «Je suis si ignorante, en musique surtout! [...] Jamais une étude suivie et sérieuse n'a hanté mon cerveau manquant essentiellement de solidité. [...] Mon destin a été très âpre, très fou, très infortuné, accompagné d'une médiocre santé sur une constitution robuste. J'ai eu tant à souffrir moralement et physiquement. [...] Les voyages, dissipateurs de chagrin, ont plus tard absorbé mes années plus mûres, et je suis arrivée à la vieillesse, sans aucun bagage de savoir, ayant plongé dans le sentiment désastreux et stérile la meilleure partie de ma vie [...]. Et me voici au seuil de l'éternité sans pouvoir réciter de mémoire un vers de Virgile, ni jouer par souvenir chéri un nocturne de Chopin [...]. Je vous suis bien reconnaissante de m'avoir crue à votre portée et capable de vous suivre, ligne par ligne, sur les cimes altières de la science et de l'art combinés». Son style transparaît pourtant dans d'autres passages: «Dans une transparence laiteuse se jouent les premières lueurs de l'aube; puis les 
sourires irisés de l'aurore. Le rose, indécis, passe du violet timide au pourpre orangé saupoudré d'étincelles de diamants dans une harmonie diaprée rappelant les tons délicats et fugitifs de l'opale.».

8 Nous pouvons donc attendre avec intérêt le prochain volume que nous promet Michelle Tricot sur Solange romancière, ce qui complétera son portrait. 